\title{
THE EFFECT OF GENRE-BASED MENTORING ON LINGUISTIC FEATURE QUALITY OF RESEARCH ARTICLE ABSRACTS BY INDONESIAN LECTURERS IN SOCIAL SCIENCES AND HUMANITIES
}

\author{
Dedi Jasrial1; $^{1}$ Safnil Arsyad², Arono $^{3}$ \\ Universitas Bengkulu1,2,3 \\ Corresponding author: dedi.jasrial@gmail.com
}

\begin{abstract}
Meta-discourse is one of the linguistic features that have gotten a considerable attention in writing a research article abstract recently. It is because the meta-discourse serves as a textual and interpersonal marker that can help readers to organize, classify, interpret, evaluate, and react to the contents of a propositions or meanings of sentences in the research article abstracts. However, Indonesian authors still have a problem in the use of meta-discourse based on its function in writing a research article abstract that meets to reputable international journals. The purpose of this study is to help improve the linguistic feature quality of research article abstracts written by Indonesian lecturers in social sciences and humanities in terms of the appropriate use of metadiscourse devices. This study used three stages of genre-based method following Hyland (2003): modeling, joint construction, and independent construction to mentor 20 lecturers in improving their research article abstract quality in terms of the appropriate use of meta-discourse devices in the sentences. The meta-discourse devices in the lecturers' research article abstracts was evaluated following the frameworks of meta-discourse based on its function as suggested by Hyland (2005). The result revealed that there is an important improvement on the linguistic feature quality of Indonesian lecturers' research article abstracts in terms of the appropriate use of meta-discourse devices. It implies that genre-based mentoring method has been quite effective in helping Indonesian lecturers in social sciences and humanities in writing their RA abstracts in using meta-discourse devices for a reputable international journal.
\end{abstract}

Keywords: research article abstract, linguistic feature, meta-discourse, genrebased mentoring method 
The Effect of Genre-Based Mentoring on Linguistic Feature...

\section{INTRODUCTION}

It cannot be ignored that the existence of an abstract in a research article, an academic paper, a thesis, a dissertation, and other research report is currently important. As Akbas (2012) states that abstract is important because the author briefly introduces what the author has done and found, and it is an important point to be known by readers in the same community. Likewise, abstract serves as a promotion tool to attract and persuade the readers to read the entire article (Arsyad, 2014; Emilia, 2009; Pho, 2008; Hyland, 2000). Therefore, research article abstract contains the important point of whole paper to help the readers understand simply the basic idea in a scientific work.

Regarding the importance of abstracts, authors need to know the proper ways to write a qualified research article abstract for international journals. One of those ways is by involving meta-discourse devices in writing a sentence in research abstract as a form of linguistic realization in academic writing. According to Mirshamsi and Allami (2013), metadiscourse is used to help the authors or speakers to interact with the readers or receivers of their texts. Further, Hyland (2005) suggests that authors should use the meta-discourse devices in academic writing as presented in the table below;

Table: 1 Types of Meta-discourse in Academic Texts (Hyland, 2005, p. 49)

\begin{tabular}{|c|c|c|}
\hline Category & Function & $\begin{array}{l}\text { Examples from the } \\
\text { corpora }\end{array}$ \\
\hline \multicolumn{3}{|c|}{ Interactive Meta-discourse } \\
\hline Transitions & $\begin{array}{l}\text { Connection between steps in } \\
\text { argument }\end{array}$ & $\begin{array}{l}\text { Thus, although, and, } \\
\text { however }\end{array}$ \\
\hline Frame markers & $\begin{array}{l}\text { Discourse acts, sequences or } \\
\text { stages }\end{array}$ & The purpose of the study \\
\hline Endophoric markers & $\begin{array}{l}\text { Information on other parts the } \\
\text { text }\end{array}$ & The first chapter \\
\hline Evidential & Information from other texts & $\begin{array}{l}X^{\prime} s \quad(1980) \text { observation } \\
\text { about }\end{array}$ \\
\hline Code glosses & Additional information & Such as, including, e.g. \\
\hline \multicolumn{3}{|c|}{ Interactional Meta-discourse } \\
\hline Hedges & Subjectivity of a position & Possible, may, seem \\
\hline Boosters & Expressing certainty & Clear, somewhat, suggest \\
\hline Attitude markers & Writer's attitude to proposition & $\begin{array}{l}\text { Appropriate, bets, } \\
\text { surprisingly }\end{array}$ \\
\hline Self-mentions & Author's (s) presence & I \\
\hline Engagement markers & $\begin{array}{l}\text { Building relationship } \\
\text { reader }\end{array}$ & Note that \\
\hline
\end{tabular}


As shown in table 1, the meta-discourse consists of two types, such as interactive and interactional meta-discourse. Both of them have different function. As Keshavarz and Kheirieh (2011) mention that interactive metadiscourse refers to "elements that are used to help the writer organize the discourse and arguments in a way that they convey the writer's intended meaning", while interactional meta-discourse refers to "the writer's feelings, attitudes and degree of commitment toward the text" (p. 6). Therefore, the aim of meta-discourse devices used by the authors in academic writing is to adjust the level of personality in their texts, and to offer a representation of themselves and their arguments. It will help the readers easier understand, comprehend, organize, interpret, and evaluate the information that presented in the text, including the research article abstract.

Meta-discourse is part of discourse structure that has a function to add the quality of research article beside the rhetorical structure (i.e. communicative unit of moves). The authors should make meta-discourse appropriately when they write each section of research article (abstract, introduction, method, results and discussion, and conclusion), so that their research article quality meets to discourse structure of international journals. However, Adnan's (2009) study found that one of Indonesian authors' problems in writing research article for international journal was structure transfer (discourse) in second language acquisition. In regarding to metadiscourse, Azizah and Budiman (2017) state that Indonesian graduate students still have a problem to make hedges in writing a research article; they are still confused how to use it appropriately. Whereas, the other problem faced by Indonesian authors is the journals' high standard in terms of language and content including of the research article abstract (Arsyad \& Adila, 2017). Thus, those findings and statements imply that the Indonesian problems in writing a research article are in terms of content, and language (i.e. discourse structure). Consequently, journal editors often rejected Indonesian's manuscripts.

In the field of social sciences and humanities, Renandya (2014) reports that RELC journal's rejection rate is over $90 \%$, ELTWO has a rejection rate of $50-60 \%$, and so does other journals in the language education fields such as ELT journal, Applied Linguistics and TESOL quarterly. Renandya further explains that the reasons of rejection from the journals' editors are vary, such as poorly writing quality, language errors, scope, and aims of the journals do not match, and do not follow the submission's guidelines. Similarly, Ehara and Takahashi (2007) also state that the important cause of manuscript rejection is language barrier, but it is not the sole factor. Meanwhile for Indonesian authors' problem, Adnan (2009) explains that the ultimate reason of rejection is the inability of Indonesian authors followed the discourse structure of international journals to express their ideas in writing the 
research article. The discourse structure in this case means that the manuscripts rejection caused by the inappropriate use of meta-discourse devices in the research article abstract.

The problems faced by Indonesian lecturers in social sciences and humanities in writing a research article abstract in terms of meta-discourse usage can be solved using genre-based mentoring method (GBMM) which developed from teaching and learning stage of genre theory that called as genre-based approach (GBA). It is because GBA is an approach to teaching writing that has directions for the learners (Martin, 1993 as cited in Elashri, 2013).Meanwhile, the direction in the GBMM was done collaboratively among the participants, mentor, and instructor in writing process (i.e. choosing the appropriate meta-discourse devices for each sentence in research article abstracts). The collaboration was done in three main stages by following Hyland (2003, p. 21); namely (1) Modeling, (2) Joint construction, and (3) Independent construction. Therefore, the use of GBMM for this study aimed to help improve the linguistic quality of research article abstracts written by Indonesian lecturers in social sciences and humanities before submitting their research article manuscripts to reputable international journals.

Several researchers had done studies about meta-discourse analysis in research article abstracts, such as (Liu \& Huang, 2017; Wang \& Zhang, 2016; Mocanu, 2015). These studies examined the meta-discourse in different disciplines. The findings show that there was a different use of metadiscourse devices in research article abstracts in different disciplines. The dominant of meta-discourse devices among disciplines was hedges. It means that each journal in different disciplines has different characteristic in using meta-discourse. Then, Nagao (2018), Burgos (2017), Elashri (2013), and Batubara (2013) did the studies about genre-based approach. Those studies found that GBA could improve students' writing ability in different genres (i.e., descriptive text, argumentative and expository essay), attitude, and performance.

The previous studies above had found that the ideal of meta-discourse devices for research article abstract that had published in reputable international journals, and the use of GBA for teaching writing in terms of text types in English. However, there is no study as far as those authorsare concerned on improving the linguistic feature quality in terms of the appropriate use of meta-discourse in Indonesian lecturers' research article drafts for international journals by using genre-based mentoring method. This is the rationale for this study; that is toprove or disprove the effectiveness of genre-based mentoring on linguistic quality of research 
article abstracts by Indonesian lecturers in social sciences and humanities. To address the issue, the research question of this study was;

a. How can genre-based mentoring method help improve the linguistic features quality of RA abstract in terms of the appropriate metadiscourse use written by Indonesian university lecturers in Social Sciences and Humanities in Bengkulu?

\section{METHOD}

\section{Research Design and Research Participants}

The design of this study was a descriptive qualitative and quantitative method that called as a mix method. Gay, Mills, and Airasian (2011) state that mixed method designs is the combination between quantitative and qualitative approaches and the data of the study must be in form of quantitative and qualitative. The distribution of participants in this study is presented in this table below:

Table: 2 Distributions of Research Participants

\begin{tabular}{clccc}
\hline No & \multicolumn{1}{c}{ Universities } & Codes & $\begin{array}{c}\text { Number of } \\
\text { Participants }\end{array}$ & Percentage \\
\hline 1 & University of Prof. Hazairin, S.H & UH & 2 & $10 \%$ \\
2 & $\begin{array}{l}\text { Muhammadiyah University } \\
\text { Bengkulu }\end{array}$ & MUB & 3 & $15 \%$ \\
3 & Dehasen University of Bengkulu & DUB & 4 & $20 \%$ \\
4 & State Islamic Institute of Bengkulu & SIIB & 1 & $5 \%$ \\
5 & University of Bengkulu & UB & 11 & $55 \%$ \\
\hline & & & & \\
& Total & $\mathbf{2 0}$ & $\mathbf{1 0 0 \%}$ \\
\hline
\end{tabular}

As shown in table 2, the participants of this study were chosen purposefully and the number of research participants among different universities and institute is not equal; this is because there was a difference in term of the number of lecturers in each university and institute who have written an RA draft.

\section{Instruments}

The instrument of this study was observation sheet developed from the meta-discourse' frameworks of Hyland (2005). The observation sheet used as a tool to identify sentences, words, and phrases that indicated as a metadiscourse device in the research article abstracts of the participants, and comments about the inappropriate meta-discourse usage in the sentences. Then, the number of possible meta-discourse based on its category was displayed in table. The last, all data analysis results was calculated. 
The Effect of Genre-Based Mentoring on Linguistic Feature...

\section{Genre-Based Mentoring Method Procedures}

This study applied genre-based mentoring method by following the model of teaching learning stage from Hyland (2003, p. 21). This model was chosen because it was simpler and one of the most recent models compared to other modelsas suggested by Feez and Joyce (2002), and Rhothery and Stenglin (1994, as cited in Dirgeyasa, 2016). The Hyland's model is presented below:

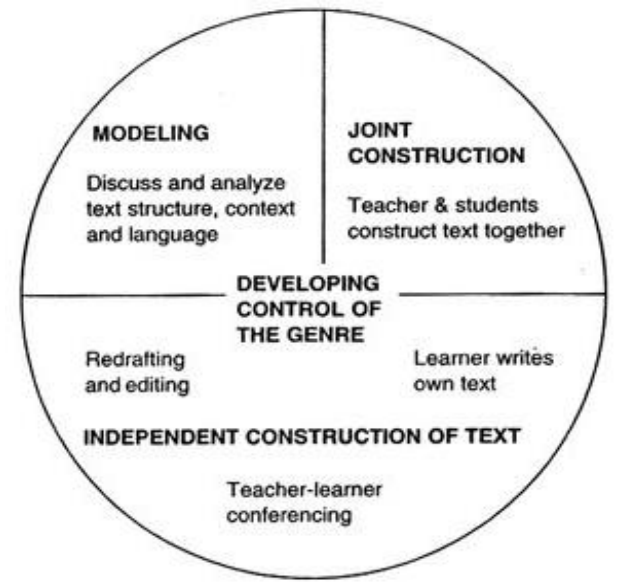

Figure 1. Model of the teaching and learning cycle (Hyland, 2003, p. 21)

As shown in Fig. 1, Hyland's model has three stages in implementing the genre-based approach in the teaching of writing; (1)modeling and deconstructing a model of text, (2) joint construction, and (3) independent construction. Each stage consisted of one workshop, so that there were three workshops done in implementing the genre-based mentoring method. The detail explanation of each stage in implementing genre-based mentoring in the workshop is as follow.

\section{Modeling}

The researcher held this stage in the first workshop. The activities in modeling stage are the students and teachers analyze and discuss the structure, context, and language in the text of a genre (Hyland, 2003). The aims of analysis process in the modeling process is to know the nature of text's features (i.e, linguistic features, text structure, and communicative purpose of text (Dirgeyasa, 2016). In addition, the building the context of text was also carried out before doing the analysis process. It was done by an instructor who an expert in academic writing in presentation activity. The instructor built the knowledge of participants in terms of linguistic features (i.e meta-discourse devices) of a research abstract based on standard international journal. 
In building the knowledge, the expert shared his experiences, knowledge, and showing a sample of good research article abstract, that had published in an international journal to the participants. The second activity in the modeling stage was the instructor asked the participants to submit their research article abstract. These drafts become the first draft of the study. Then, the instructor analyzed the drafts by seeing the appropriate use of meta-discourse. The analysis results of the drafts contained comments about the participants' drafts. After that, the participants and the researcher together discussed the comments, for examples; inappropriate metadiscourse devices in a sentence. The researcher and participants did the discussion via face-to-face mode at University of Bengkulu in a workshop.

\section{Joint construction}

This stage was held in the second workshop. This workshop produced the second draft. Rivera (2012) states that the teacher's role in the joint construction stage is to guide students to create a new text that matches with the target genre. Therefore, in genre-based mentoring method, there was also collaboration between the researcher and the participants in this stage.

The aim of collaboration is to give the supports for the participants in using linguistic resources and writing skill (Ong, 2016). The linguistic resources refer to meta-discourse, while research article abstract refers to writing ability. The researcher, instructor and the participants worked together in revising or rewriting a sample of research article draft using the knowledge and experience that the participants obtained from the first stage. For example, the researcher and the participant chose the some appropriate meta-discourse features in a sentence.

\section{Independent Construction}

This stage was held in the third workshop. This workshop produced the third draft. According to Nagao (2018), the independent construction stage is a process of constructing a text that done by students independently with use all the knowledge that they have obtained in the previous stage. In this stage, the participants started to reconstruct their own research article abstract drafts independently. The participants used all the knowledge that they had obtained before in the first stage and the result of construction of research article abstract in the second stage. The participants edited or rewrote their own research article abstract drafts. In addition, in genre-based mentoring method, there was still a little discussion done between the researcher and the participants in this stage who still need a help in reconstruction their own drafts, but the researcher's role in this stage was not as active as in the first and the second stage. 
The Effect of Genre-Based Mentoring on Linguistic Feature...

\section{Data Analysis}

This study used genre-based discourse analysis or communicative purpose analysis (CPA) to analyze the drafts of the workshopparticipants. The ways of identifying the communicative purpose and discourse clues in the research article abstract drafts that categorized as meta-discourse devices following the steps from Arsyad (2014).

First, the researcher read carefully the entire article to understand the research project. Second, researcher read the abstract drafts of the research to get a better understanding. Third, the abstract drafts of the research article read again to identify the possible meta-discourse in each sentence. Fourth, the possible meta-discourse devices in each sentence of research article abstracts were coded based on meta-discourse category. Finally, the possible meta-discourse devices cited into observation sheet based on meta-discourse category to calculate all the data analysis result. Then, data analysis results were calculated and displayed in a table.

To avoid the subjectivity of the analysis from the researcher, an independent rater was involved in this study as a co-rater. The co-rater was an alumnus of postgraduate program of English language education of University of Bengkulu and an English teacher at a Vocational School in Bengkulu. The researcher trained her intensively before analyzing the drafts to get better understanding on meta-discourse. After that, she had two months to analyze $60 \mathrm{RA}$ abstracts from the corpus of the study. The result of inter-rater correlation agreement was $88.89 \%$ or 0.88 . This result was in an excellent category agreement (Brown, 1996 as cited in Kanoksilapatham, 2005). The difference occurred in identifying and coding boosters, attitude markers, and transitions. After a few discussions between the researcher and the co-rater, full agreement was finally achieved.

\section{Research Article Abstracts Evaluation}

Lecturers' RA abstracts were evaluated following the meta-discourse frameworks suggested by Hyland (2005). The frameworks used as guidelines to evaluate the meta-discourse quality of the lecturers' RA abstract drafts, because it is an ideal framework for standard international journal. It was used as a guideline to examine and evaluate the linguistic features (i.e. the appropriate use of meta-discourse device) of the lecturers' RA abstracts as the participants of this study from the first, second, and third drafts. The RA abstract drafts that have more appropriate meta-discourse devices based on the frameworks were the better RA abstracts. To know the improvement, the researcher compared the number of appropriate item of the meta-discourse device in the RA abstract drafts from draft 1 to draft 3 . 


\section{FINDINGS}

The data analysis results after applying genre-based mentoring method show that there is an important improvement on linguistic features quality of RA abstracts written by lecturers in social sciences and humanities in Bengkulu from draft 1,2, and 3 in terms of the appropriate use of metadiscourse.

In this study, there were two categories of meta-discourse used by the lecturers in their RA abstracts, namely interactive and interactional metadiscourse. The frequency of meta-discourse devices in the lecturers' RA abstract drafts from draft 1 to draft 3 is presented in the following table.

Table: 3. The Distribution of Meta-discourse in the Lecturers' RA Abstracts

\begin{tabular}{|c|c|c|c|c|}
\hline \multicolumn{2}{|c|}{ Meta-discourse Category } & Draft 1 & Draft 2 & Draft 3 \\
\hline & Transition & 87 & 89 & 110 \\
\hline Interactive & Frame Markers & 19 & 32 & 37 \\
\hline Meta- & Evidentials & 4 & 4 & 5 \\
\hline discourse & Code Glosses & 28 & 32 & 34 \\
\hline Interactional & Hedges & 19 & 27 & 32 \\
\hline Meta- & Boosters & 27 & 35 & 35 \\
\hline discourse & Attitude Markers & 8 & 11 & 15 \\
\hline & Self-Mentions & 2 & 0 & 0 \\
\hline & Engagement Markers & 2 & 2 & 2 \\
\hline
\end{tabular}

As shown in table 3, the interactive meta-discourse is used in four categories, namely transitions, frame markers, evidential, and code glosses. Meanwhile, interactional meta-discourse also found in five categories, namely hedges, boosters, attitude markers, self-mention, and engagement markers. The frequency of interactive meta-discourse devices had increased in four categories of lecturers' RA abstract drafts.

For examples, the appearance frequency of transitions had increased from 87 items in draft 1 to 110 items in draft 3, frame markers had increased from 19 items to 37 items in draft 3, evidential had increased from 4 items to 5 items in draft 3 , and code glosses had increased from 28 items in draft 1 to 34 items in draft 3 . In addition, the frequency of interactional meta-discourse devices had increased in four categories and reduced in one category. For examples, the appearance frequency of hedges had increased from 19 items in draft 1 to 32 items in draft 3, boosters had increased from 27 items in draft 1 to 35 items in draft 3 , attitude markers had increased from 8 items in draft 1 to 15 items in draft 3, engagement markers had increased from 2 items in draft 1 to 3 items in draft 3, and self-mentions had reduced from 2 items in draft 1 to 0 item in draft 3 . 
The Effect of Genre-Based Mentoring on Linguistic Feature...

\section{Extract 1}

However, the symbols of the Islamophia..., because it has labeled Islam as a terrorist religion.(Transition-DUB-Sri and Vet).

As can be seen in Extract 1, the writers used transition devices in writing their sentences, for examples; however and because. The function of the transition devices is to connect between the steps in authors' argument and to make the background of their RA abstracts more argumentative.

\section{Extract 2}

The purpose of this paper is to describe influence of guided imagery techniques ... (Frame Marker-Move-2-UB-Way and Ish).

As shown in extract 2, the writers used a frame marker device to state the research' purpose, such as "the purpose of this paper". The function of this frame marker device in the example above is as a discourse act to address the purpose of the writer did the study.

\section{Extract 3}

Relaxation techniques such as guided imagery have been used to treat a variety of student anxiety ... (Code Glosses-UB-Way and Ish).

The example in extract 3 above shows that the writers used a code glosses device to provide additional information about the relaxation techniques (i.e. such as). The function of the code glosses device in the example above is as additional information to support the main idea of the sentence.

\section{Extract 4}

Following the model suggested byLoan and Pramoolsook (2015) ... (Evidentials-Move-3-UB-Was, Saf and $\mathrm{Al}$ ).

As can be seen in Extract 4, the writers used an evidential device (i.e. Loan and Pramoolsook (2015)) to address the theory that they used as a methodology of their study. It aims to inform readers about the reference that they cited from other texts.

\section{Extract 5}

a. ... thismay be problematic for university students or new writers especially when writing in a language ... (Hedges-MUB-Rin, Saf, and Way).

b. ...the symbols of Islam used by a community on certain activities can build a negative stereotype ...(Hedges-DUB-Sri and vet).

As can be seen in extract 5 ( $a$ and $b$ ), the writers had used hedges devices in writing the sentence, such as, may and can. Word "may" in extract $9 \mathrm{a}$ is to state position of writers' claim about the problems faced by 
university students. In extract 9b, the writers used word "can" to state their claim about the symbols of Islam that build a negative stereotype in certain community. The use of hedges devices in the examples above had shown subjectivity from the writers in writing their RA abstract draft so that the positive communication through a text between writers and readers can be achieved. In addition, authors can avoid objections about the writers' claims from other parties.

\section{Extract 6}

The results show that two authorial stances: neutral and positive stances...(Boosters-UB-Suc, Saf and Aro).

As can be seen in extract 6, the writers had used a booster device in writing their sentences to state the result of their study in the research article abstract. Word "show" is to state the writer's certainty expression about their research results. This example shows that the use of booster in writing the RA abstract is to express the writers' certainty or to emphasize a point that they believed.

\section{Extract 7}

The discussion section is considered the most important section of a thesis but also the most difficult to write especially by university students (Attitude Markers-Move-1-BU-Was, Saf, and Al).

As can be seen in extract 7, the writers used an attitude marker in writing the sentences to introduce the background of their study, such as "the most important, and the most difficult". The term of "the most important" is to express the writers' attitude about the position of discussion section in a theses and the term of "the most difficult" is to express that the discussion section is not easy to be written. The use of attitude markers in writing RA abstract can be form of adjective and they inevitably indicate the writers' attitude to what they write or say.

\section{Extract 8}

Grammar is one of the language knowledge that must be mastered by

English students. (Engagement Markers-UB-Wis, Em, and Ilz.).

The example in extract 8 above shows that the writers used an engagement marker in form of modality "must" to state their claim. It aims to inform readers about the importance of mastering English grammar for English students. It can also build a relationship between writers and readers through a text.

\section{DISCUSSION}

As described in the previous section, the lecturers used appropriate metadiscourse devices in writing their RA abstracts. The appearance frequency of 
The Effect of Genre-Based Mentoring on Linguistic Feature...

meta-discourse devices in the lecturers' RA abstract had improved from draft 1, 2 and 3. It implies that the lecturers might have understood the function of meta-discourse in writing RA abstracts or in academic text. Hyland (2005) states that meta-discourse is linguistics features in communication not only to show the writers' position, such as attitude, personalities, and assumptions to the reader but also provide coherent and related ideas from one to another. The use of meta-discourse features will also create communication between the writers and the readers

The lecturers had used interactive meta-discourse, such as transition, frame markers, evidential, and code glosses. Arsyad and Arono (2018) mention that the use of transition and frame marker markers will create text to be more cohesive. Meanwhile, Evidentials and code glosses feature will help readers to get detail information in text. In addition, the lecturers also involved the interactional meta-discourse devices in writing the RA abstracts, such as hedges, attitudinal markers, boosters, engagement markers. Zhang et al (2012) mentions that the interactional meta-discourse (i.e., hedges and attitudinal markers) must be frequently used by author because these markers are evaluative and subjective from the author such as in supporting the choice of research topics, research methods, results or findings and conclusions to convince readers that research is important, interesting, valid, and reliable. It implies that the use of meta-discourse in RA abstract can improve the rhetorical quality of writers' RA abstract.

The results of this study in terms of meta-discourse usage in RA abstracts were in line with the results of study from Wang and Zhang (2016). Wang and Zhang also found that the frequency usage of interactive metadiscourse in two disciplines of academic article journals (i.e. mathematical and linguistics) was more frequently found in both RA journals than interactional meta-discourse. Based on the study from the researcher and Zhang and Wang (2016), they found six features that the most dominant exist in meta-discourse. The most dominant features exist in interactive meta-discourse are transitions, frame markers, and code glosses. Meanwhile, the most dominant features exist in interactional meta-discourse are hedges, boosters, and attitude markers. These findings imply that those features are the most important to be included more frequently in writing the research article abstracts and the lecturers' RA abstracts have been the same as international journal standard. Thus, these evidences and explanation of findings of this study indicate that the RA abstract drafts of the lecturers have become better in terms of linguistic features quality style. The function of meta-discourse is to create a coherent and cohesive text. Each linguistics feature has its own function that contributes to make a genre to be more communicative 
The improvement of the RA abstracts quality of the lecturers in terms of the meta-discourse usage also show that genre-based mentoring is an effective method in teaching and learning writing for Indonesian lecturers before submitting to international journals. The effectiveness of this method is because it has three stages of writing process cycle that developed from genre-based approach. These stages were able to improve the lecturers' knowledge on choosing the appropriate use and the importance of metadiscourse as a linguistic realization in writing a RA abstracts for reputable in international journals, especially, in modeling and joint construction stage.

In addition, Dirgeyasa (2016) claims that "Genre as an approach to teaching and learning writing is a matter of mixed approach between process and product approach" (p. 50). The genre as a process refers to the steps that followed by students and teachers in the process of writing a text, while genre as a product refers to the distinctive features of writing in terms of organization, linguistic features, writing style, rhetorical structure, and communicative purpose. The collaboration between process and product in genre-based approach aims to enable students write a better genre in academic writing based on its purpose. Moreover, Widodo (2006) states that genre-based approach educates students to use better language patterns so that the students can produce a coherent text. Thus, in the genre-based mentoring method there were processes carried out by the researcher and participants in writing a research article abstracts in terms of the appropriate use of meta-discourse. The processes in the genre-based mentoring method were; 1) the participants and researcher together analyzed the use of metadiscourse device in each sentence of the research article abstract, and discuss the results of analysis in the modeling stage. 2) The participants and the researcher worked together choosing the appropriate meta-discourse device for each sentences in research article abstracts in the joint construction stage. 3) The participants revised their own RA abstract drafts in groups or individually. As a result, better research article abstract drafts was produced based on linguistic feature quality of reputable international journals after applying the genre-based mentoring method.

The findings of this study were in line with those of Nagao (2018), Burgos (2017), Elashri (2013), and Batubara (2013) who found that genrebased approach was effective to improve the students' writing ability. First, Nagao's (2018) findings show that GBA could improve students' awareness of generic structure and interpersonal meaning in writing argumentative essays. Second, Burgos (2017) found that GBA could help students to understand the moves and linguistics features of expository essay. Third, the study from Elashri (2013) revealed that students' writing ability and their positive writing attitude improved after applying GBA. The last, Batubara (2013) found that that GBA was able to improve students' ability in writing a 
The Effect of Genre-Based Mentoring on Linguistic Feature...

narrative text viewed from students' ability in producing a narrative text based on its structure and language.

The findings of this study and the previous studies, it indicates that the genre-based mentoring method supports the effectiveness of the genrebased approach for teaching writing. It is not only for EFL students who learn writing of a model of genre (i.e. text types and essays) but also for lecturers who learn writing the genre of RA for reputable international journals.

\section{CONCLUSION}

As described in the previous section, it can be concluded that linguistic features quality of the lecturers' RA abstracts in social sciences and humanities had improved from draft 1,2, and 3. The improvement of linguistic feature quality of the lecturers' RA abstracts was viewed from the frequency the appropriate use of meta-discourse from draft 1,2 , and 3 . It implies that genre-based mentoring method has been quite effective in helping Indonesian university lecturers in social sciences and humanities in Bengkulu in writing the RA abstracts based on international journal linguistic feature before submitting their manuscripts to a reputable international journal.

\section{REFERENCES}

Adnan, Z. (2009). Some potential problems for research articles written by Indonesian academics when submitted to international English language journals. The Asian EFL Journal Quarterly, 11(1), 107-125.

Akbas, E. (2012). Exploring meta-discourse in master's dissertation abstracts: Cultural and linguistic variations across postgraduate writers. International Journal of Applied Linguistics and English Literature, 1(1), 1226

Arsyad, S. (2014). The discourse structure and linguistics features of research article abstracts in English by Indonesian academics. The ASIAN ESP Journal, 10(2), 191-224.

Arsyad, S., \& Adila, D. (2017). Using local style when writing in English: the citing behaviour of Indonesian authors in English RA introductions.Asian Englishes,1-16.

Arsyad, S., \& Arono. (2018). Memahami dan menulis abstrak artikel jurnal. Jakarta: Halaman Moeka Publishing.

Azizah, U. A., \& Budiman, A. (2017). Challenges in writing academic papers for international publication among Indonesian graduates students. JEELS, 4(2), 176-197. 
Batubara, S. S. (2013). The implementation of a genre-based approach: a case study in teaching a narrative text to second grade junior high schools students. English Education, 1,(2), 139-160.

Burgos, E, G. (2017). Use of the genre-based approach to teach expository essays to English pedagogy students. How, 24(2), 141-159.

Dirgeyasa, I. W. (2016). Genre based approach: what and how to teach and learn writing. English Language Teaching, 9(9), 45-51.

Ehara, S., \& Takahashi, K. (2007). Reasons for rejection of manuscripts submitted to AJR by international authors. American Journal Roentgenology, 188(2), 113-116.

Elashri, I, I, E, A. (2013). The effect of the genre-based approach to teaching writing on the EFL Al-azhr secondary students' writing skills and their attitudes towards writing (Ph.D Dissertation). Mansoura University, Egypt.

Emilia, E. (2009). Menulis Tesis dan Desertasi. Bandung: Alfabeta

Feez, S., \& Joyce, H. (2002). Text-based syllabus design. Sydney, NSW: Ames.

Gay, L. R., Mills, G. E., \& Airasian, P. W. (2011). Educational research competencies for analysis and applications (10 th Ed.). New Jersey: Pearson.

Hyland, K. (2000). Disciplinary Discourse: Social Interactions in Academic writing. London: Longman.

Hyland, K. (2003). Second language writing. Cambridge: Cambridge University Press.

Hyland, K. (2005). Meta-discourse: exploring interaction in writing. London: Continuum.

Kanoksilapatham, B. (2005). Rhetorical structure of biochemistry research articles. English for Specific Purposes, 24, 269-292.

Keshavarz, M. H., \& Kheirieh, Z. (2011). Metadiscourse elements in English research article written by native English and non-native Iranian writers in applied linguistics and Civil Engineering. Journal of English Studies, 1(3), 3-15.

Liu, P., \& Huang, X. (2017). A study of interactional meta-discourse in English abstracts of economics research articles. Higher Education Studies, 7(3), 25-41. http:/ / doi.org/10.5539/hes.v7n3p25.

Mirshamsi, A., \& Allami, H. (2003). Metadiscourse markers in the discussion/conclusion section of Persian and English master's theses. The Journal of Teaching Language Skills, 5(2), 362-377.

Mocanu, M. (2015). An empirical analysis of metadiscourse in the abstracts of Romanian accounting research articles.Accounting and Management Information System, 14(2), 362-377.

Nagao, A. (2018). A Genre-based approach to writing instruction in EFL classroom context. English Language Teaching, 11(5), 130-147. 
Ong, W. N. (2016). Using genre-based instruction to teach the writing of literacy criticism. Gema Online of Language Studies, 16(1), 35-48.

Pho, P. D. (2008). Research article abstracts in applied linguistics and educational technology: A study of linguistic realizations of rhetorical structure and authorial stance. Discourse Studies, 10(2), 231250.https:/ / doi.org/10.1177/1461445607087010.

Renandya, W. (2014). Choosing the right international journal in TESOL and Applied Linguistics. English Language Teaching, 6, 2-17.

Rivera, J. D. H. (2012). Using-genre based approach to promote orall communication in the classroom in the Colombian English classroom. Colombia Applied Linguistic Journal, 14(2), 109-126.

Wang, L., \& Zhang, Y. (2016). An analysis of meta-discourse in the abstracts of English academic papers.Global Journal of Human-Social Science: Linguistics and Education, 16(9).

Widodo, H. P. (2006). Designing a genre-based approach lesson plan for an academic writing course.English Teaching Practice and Critique, 5(3), 173199.

Zhang, B., Thuc, Q, B, T., Pramoolsook, I. (2012). Moves and linguistic realizations: English research article abstracts by Vietnamese agricultural researchers. The Asian ESP Journal, 8(3), 126-149. 